\title{
The Influence of CrAlN Coating Chemical Composition on Soldering Resistance in Contact with Al-Si-Cu Alloy
}

\author{
Pal Terek ${ }^{1}$, Dragan Kukuruzović ${ }^{1, *}$, Lazar Kovačević ${ }^{1}$, Aleksandar Miletić ${ }^{1}$, Vladimir Terek ${ }^{1}$, \\ Branko Škorić ${ }^{1}$, Peter Panjan ${ }^{2}$, and Miha Čekada ${ }^{2}$ \\ 1 University of Novi Sad, Faculty of technical sciences, Trg Dositeja Obradovića 6, 21000, Novi Sad, Serbia; \\ terekpal@gmail.com (P.T.); lazarkov@uns.ac.rs (L.K.); miletic@uns.ac (A.M.); vladimirterek@uns.ac.rs \\ (V.T.); skoricb@uns.ac.rs (B.Š.); \\ 2 Jožef Stefan Institute, Ljubljana, Slovenia; peter.panjan@ijs.si (P.P.); miha.cekada@ijs.si (M.Č.) \\ * Correspondence: kukuruzovic@uns.ac.rs
}

Received: 4 April 2020; Accepted: 12 May 2020; Published: 14 May 2020

\begin{abstract}
During the high pressure die casting (HPDC) process the die material is exposed to thermal fatigue, erosion, and corrosion. Corrosion leads to the soldering of cast alloy to tool surfaces which consequently bonds the casting with die material. Besides wear, such a process reduces the casting quality, production efficiency, and endanger the tool integrity. Application of thin ceramic coatings on die surfaces reduces the soldering effects and improves the die performance. However, the development of ceramic coatings for these purposes still requires detailed information on the phenomena involved in these processes. In this study, the soldering performance of a complex nanolayer CrAlN coatings, with three chemical compositions (high- $\mathrm{Cr}$, balanced $\mathrm{Cr}$ : $\mathrm{Al}$ and high-Al content) were evaluated. The cast alloy soldering was evaluated by the detachment test in three configurations. In this test, a simple casting is formed in contact with flat coated surfaces. Upon casting solidification, the formed joint is dismantled and a force required for this process was recorded. To characterize and quantify the exhibited wear after detachment test surfaces of coated samples were analyzed by different microscopy techniques. Two forms of wear were detected on investigated samples. Cast alloy soldering processes induced formation of thin layers of cast alloy on the surfaces of all investigated coatings. Additionally, substrate corrosion through the coating growth defects caused coating layer delamination during the detachment test. The evaluated coatings displayed different behaviors regarding the extent of wear and values of detachment force. The coating with balanced CrAlN composition exhibited the best soldering and corrosion resistance and displayed the lowest ejection force. In terms of soldering and corrosion resistance, the high-Al coating outperformed the high-Cr content coating. However, high-Al and high-Cr coating exhibited significantly higher and quite comparable values of detachment force. Based on the quantitative results it was postulated that, besides soldering and substrate corrosion, the casting-coating bonding strength depends also on "pure" sticking effects of cast alloy to coated surfaces.
\end{abstract}

Keywords: HPDC; aluminum alloy; cast alloy soldering; detachment test; nanolayer coating; CrAlN; corrosion; delamination

\section{Introduction}

HPDC process is a mass production process used for production thin-walled components with complex shapes and fine surface finish. During this process, molten metal is injected into a preheated die (tool) cavity with high velocity and pressure. Materials usually processed by HPDC technology are aluminum, magnesium, zinc, and their alloys. Representative parts produced by this technology 
of aluminum alloy are different kinds of housings, engine blocks, engine heads, and automobile structural parts.

During HPDC production the die surface is exposed to extreme conditions which lead to thermal fatigue, erosion, corrosion, cast alloy soldering, and abrasion wear [1,2]. Cast alloy soldering is a process in which molten reacts with die material and forms strong bonds between the casting and die material. As a consequence of the soldering process upon the casting ejection, thin layers of cast alloy remain on die surfaces [3]. This leads to the reduction of castings quality, decreased productivity, and increased production cost due to increased machine downtime [4-7]. In order to reduce the soldering effects and improve the casting ejection performance, after every casting cycle die lubricant is sprayed on die surfaces. Alternating casting and spraying cycles impose considerable thermal stress on the die surfaces which ultimately results in thermal-cycling fatigue. In practice, die lubricant is usually excessively used, which causes a significant increase in production cost and also has bad environmental effects. Therefore, its use has to be reduced as much as possible. One way to reduce the application of die lubricants is by application of protective ceramic coatings on HPDC dies. [8-10]. These layers are usually deposited by physical vapor deposition (PVD) techniques [1113]. Coatings commonly deposited used for protection of HPDC dies are thin, hard ceramic coatings based on transitional-metal nitrides and oxides and combination of these. These coatings are used because of their high hot hardness, high chemical inertness, high oxidation resistance, thermal stability, and non-wetting by molten aluminum $[12,14-16]$. Such a combination of properties ensures high corrosion, soldering, and erosion resistance of die surfaces.

In order to extend the tool life HPDC industry constantly search for new and cost-effective materials. Considering that the application of thin coatings on commonly used ("cheap") die materials is not expensive, in recent years, a lot of research is directed toward the development of coatings for HPDC dies. For these purposes, numerous approaches were developed to evaluate the coatings soldering tendency [17]. Generally, the applied tests can be divided into practical and laboratory experiments. In practical experiments, the coating performance is estimated by evaluating their performance in the actual HPDC process. These tests are costly and time-consuming. On the other side, the laboratory experiments are more controllable, flexible, cost affordable, and can isolate a specific soldering mechanism. Commonly used experiments from this group are immersion (dipping) tests. In these tests, samples are immersed into the molten alloys in order to simulate the corrosion processes in contact with cast alloy. The longer period of sample immersion in molten metal basically simulates multiple casting cycles. Soldering was evaluated by analyzing the change in sample mass before and after the immersion test, the areal coverage of corrosion products, and the thickness of soldered material $[18,19]$. Due to different problems inherent in the execution of these tests sometimes interpretation of their results is quite difficult. Additionally, besides the information about corrosion resistance and kinetics of soldering, this test does not provide a lot of practical information.

In order to overcome the drawbacks of the mentioned test a more efficient and practical laboratory tests were developed, the separation tests. Separation tests employ a casting process for the production of sample-casting assembly. In a test, the sample-casting assembly is dismantled usually by tensile testing machine, and a force required to perform such a process is recorded. This force is a measure of a bonding strength obtained between the sample and the casting material $[17,20]$, i.e. the soldering tendency between paired materials. Examination of their surfaces provides additional information about the soldering proses. Based on the relative movement performed between the sample and the casting during the separation, these tests can be divided into the ejection test $[11,17]$ and the detachment test $[20,21]$. The ejection test is used for the evaluation of cylindrical pin samples overlapped by the casting, while the detachment is developed for evaluation of flat sample surfaces. Considering that HPDC die comprises elements of both kinds (cylindrical, flat) both tests have their special application purpose. During the pin ejection process, the pin surfaces slide over the casting material, and cast alloy galling is induced. Such a process changes the morphology of a soldering layer and contributes to the increase of its thickness [17]. This means that ejection test does not consider the soldering effects alone. 
A detachment test was developed to overcome the difficulties and drawbacks of the ejection test. In the detachment test, the contact between the casting and the sample is established over a flat surface. Given that in this test the sample-casting separation is performed perpendicular to the contact surface the soldering layer is not influenced by the casting sliding process. Accordingly, the effects of the soldering process are isolated and can be easily evaluated on flat surfaces. This procedure forms a mirror-like image between the sample and the casting which enables a detailed evaluation of the processes developed between the paired materials.

Nowadays, single-layer coatings for HPDC dies are slowly replaced by more advanced nanostructured and nanocomposite coating. The reason for this lies in their higher hardness, fracture resistance, higher oxidation, and corrosion resistance which is due to a large number of phase boundaries in their structure [14]. Additionally, due to the incorporation of ductile layers into the nanolayer coating, higher resistance to thermal-cycling fatigue can be obtained [12]. In recent years chromium-based coatings such as CrAlN [12], AlCrN [13,14], AlCrSiN [13], $\mathrm{AlCrN} / \mathrm{Si}_{3} \mathrm{~N}_{4}$ [13], $\mathrm{CrN} / \mathrm{AlN} / \mathrm{Al}_{2} \mathrm{O}_{3}[14]$ of different design received considerable attention in protection of HPDC tools. However, in the literature form the field the effects of the different chemical composition of CrAlNbased coatings are not detailly addressed.

This study aimed to investigate the soldering performance of duplex nanolayer CrAlN (CrAlN/CrN/CrAlN/AlN) coating with three chemical compositions in contact with Al-Si-Cu cast alloy. Soldering was evaluated using the detachment test performed with three periods of cast alloy contact with coating surfaces.

\section{Materials and Methods}

\subsection{Samples Preparation and Coating Deposition}

All samples used in this study are produced in the shape of discs with dimensions of $\phi 30 \times 5$ $\mathrm{mm}$. Discs were produced of a quenched and double tempered AISI H11 steel (EN X37CrMoV5-1). Samples surfaces were subjected to standard metallographic procedures for obtaining the mirror surface finish namely: grinding and polishing with $3 \mu \mathrm{m}$ diamond paste. After surface preparation, plasma nitriding was carried out in an industrial nitriding unit ION-25I (IonTech) equipped with a pulsed plasma generator. Nitriding was conducted for $12 \mathrm{~h}$ at a temperature of $510{ }^{\circ} \mathrm{C}$ using a gas ratio of $\mathrm{H} 2: \mathrm{N} 2=3: 1$, and by applying a 0.6 duty cycle. Before the deposition of the CrAlN nanolayer coatings, the compound layer that formed on the sample surface was removed by polishing with a 3 $\mu \mathrm{m}$ diamond paste. This procedure is applied on duplex layers to increase the adhesion and heat resistance of the layers.

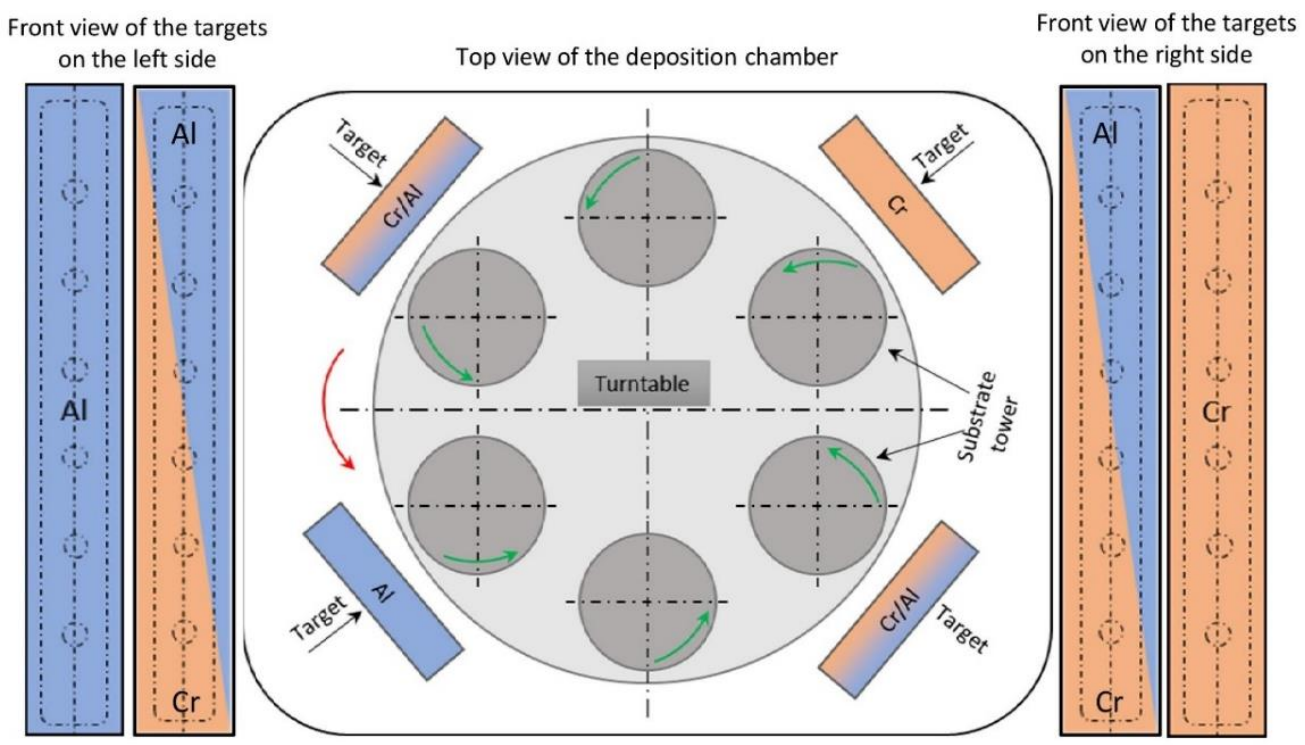

Figure 1. Schematic illustration of the deposition chamber. 
The investigated nanolayer CrAlN coating was produced with three different chemical compositions. The coatings were deposited by industrial unbalanced magnetron sputtering system CC800/9 (CemeCon). The system comprises four magnetrons placed in the corners of the chamber. By such configuration a few micrometers thick coating with nanolayer design is obtained. The investigated coating basically has few hundreds of CrAlN/CrN/CrAlN/AlN nanolayers which formed in a repeated sequence. Such design is produced using two segmental $\mathrm{Cr}-\mathrm{Al}$, one $\mathrm{Al}$, and one $\mathrm{Cr}$ target, Figure 1. After loading the chamber, it was evacuated to a pressure of $3.0 \mathrm{mPa}$. Prior to the coating deposition samples were ion-etched in mixed $\mathrm{Ar}$ and $\mathrm{Kr}$ atmosphere. Nitrogen coatings were obtained by introducing nitrogen into the chamber during deposition and keeping its flow constant during the process. During deposition bias of $-100 \mathrm{~V}$ was applied and the power on all targets was 2.5 $\mathrm{kW}$. Differences between the three coatings are in the chemical composition of CrAlN nanolayers. Different compositions are obtained by using special triangle-like segmental $\mathrm{Cr} / \mathrm{Al}$ targets. Using these targets, coatings with different $\mathrm{Cr}$ and $\mathrm{Al}$ content in $\mathrm{CrAlN}$ nanolayer are obtained at different heights in the chamber. The coatings produced with higher $\mathrm{Al}$ content are designated as $\mathrm{CrAlN}-\mathrm{Al}$; the coatings with higher $\mathrm{Cr}$ content as $\mathrm{CrAlN}-\mathrm{Cr}$ and the one with balanced chemical composition as CrAlN. All coatings were deposited using a 2-fold substrates rotation.

\subsection{Samples Characterization}

Coating adhesion was evaluated by Rockwell HRC indentation test employing a load of $150 \mathrm{~kg}$. The samples' topography was obtained on the area of $2 \mathrm{~mm}^{2}$ using 3D stylus profilometry (Talysurf, Taylor Hobson). Measurement resolution was \pm 10 of $\mathrm{nm}$ in $z$ direction, $1 \mu \mathrm{m}$ in $x$ direction and $2 \mu \mathrm{m}$ in $y$ direction. Defects density of the coatings was determined by image processing software (SPIP, Image Metrology) using 0,5 $\mu \mathrm{m}$ height threshold. The coating thickness was determined using a ball cratering test.

The samples surfaces were evaluated after detachment tests using: light optical microscopy (LOM) (Orthoplan, Leitz) and by scanning electron microscopy (SEM) equipped with X-Ray energy dispersive spectroscopy (EDS) (TH3030, Hitachi). To quantify the extent of soldering and coating delamination, LOM images were subjected to image analysis by MountainsMap software (Digital Surf). For these purposes, areas covered with soldered aluminum alloy and the areas of delamination were determined.

\subsection{Soldering Evaluation-Detachment Test}

Evaluation of coatings soldering performance is performed using a detachment test. In this test, a sample-casting material assembly is obtained by a casting process using a simple mold with a conical cavity. After the casting tests, coated samples were detached from the castings using a tensile testing machine. In this process, the force required to perform the detachment is recorded. The values of the obtained force represent the soldering tendency between the paired materials.

Evaluation of coatings soldering resistance was performed in their contact with $\mathrm{Al}-\mathrm{Si}-\mathrm{Cu}$ alloy (EN AB-46000). To ensure high-quality contact between the cast alloy and coated samples a quite high temperature $\left(750^{\circ} \mathrm{C}\right)$ of molten metal was chosen. The mold used for producing the samplecasting assembly is made of heat-resistant refractory, based on $\mathrm{Al}_{2} \mathrm{O}_{3}$ ceramic. The mold shape was developed to place a disc-shaped sample in a position where the cast alloy can be easily brought in the contact with the coated surface, Figure 2a. The diameter of circular sample-casting contact was set at $\phi 22 \mathrm{~mm}$. Prior to the casting process, the molds and samples were preheated to $650{ }^{\circ} \mathrm{C}$ and 300 ${ }^{\circ} \mathrm{C}$ respectively. For the production of sample-casting assemblies, two kinds of experiments were performed. The first kind of experiment simulates the contact of the coated sample in a short period of time, in only one casting cycle. In this test, after pouring the cast alloy into the mold, the casting was allowed to solidify in ambient air, Figure 2a. This test is designated as CS, which stands for conventional solidification. In order to simulate the effects that occur during a larger number of casting cycles, the second kind of experiment was developed. In the second kind of experiment, after pouring the cast alloy into the mold (Figure 2a), the mold with the casting was placed into the furnace 
heated to $700{ }^{\circ} \mathrm{C}$, Figure $2 \mathrm{~b}$. In this test, the mold was kept in the furnace for a defined period of time (10 $\mathrm{min}$ and $30 \mathrm{~min}$ ). After a delayed period has passed, the mold was taken out of the furnace and allowed to cool in ambient air. These tests are designated as DS10 and DS30, which stands for delayed solidification of $10 \mathrm{~min}$ and $30 \mathrm{~min}$ respectively. As a result of both kinds of experiments samplecasting assemblies are obtained, which were subjected to detachment test Figure 2c.

The detachment test was performed using a tensile testing machine (ZGIM 500). The maximal force recorded in the test is considered as a detachment force.

(a)

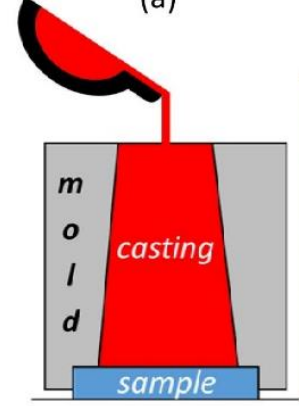

(b)

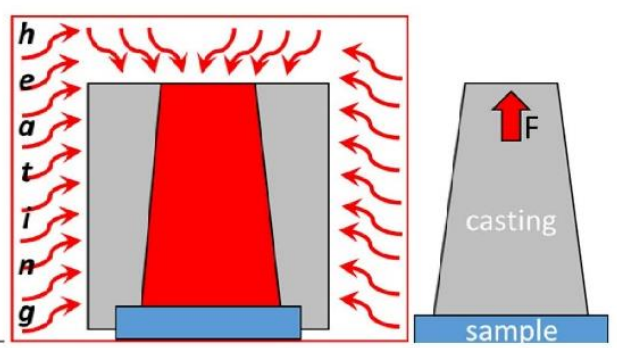

Figure 2. Schematic illustration of employed experiments: (a) pouring of cast alloy into the mold, conventional solidification; (b) delay of the solidification process, delayed solidification process; (c) sample-casting assembly and detachment test.

\section{Results}

The properties of the investigated coatings are presented in Table 1. All samples exhibited quite comparable values of surface roughness (root mean square height - Sq), while the highest values are determined for CrAlN-Cr sample. CrAlN-Cr coating also displayed the highest density of defects and areal coverage by defects. Coatings also exhibited differences in their thickness. Again, $\mathrm{CrAlN}-\mathrm{Cr}$ was the thickest coatings, CrAlN had medium thickness while CrAlN-Al is the thinnest coating.

Table 1. Samples topographic properties and thickness. Average values are determined in for three samples from each group.

\begin{tabular}{ccccc}
\hline Sample & $\begin{array}{c}\text { Sq } \\
{[\mu \mathrm{m}]}\end{array}$ & $\begin{array}{c}\text { Coating Defects Density } \\
{\left[\mathrm{num} / \mathbf{m m}^{2}\right]}\end{array}$ & $\begin{array}{c}\text { Area of Coating Defects } \\
{\left[\boldsymbol{\mu m}^{2}\right]}\end{array}$ & $\begin{array}{c}\text { Coating Thickens } \\
{[\mu \mathrm{m}]}\end{array}$ \\
\hline CrAlN & 0,15 & 121 & 11634 & 5,7 \\
$\begin{array}{c}\mathrm{CrAlN}- \\
\mathrm{Al}\end{array}$ & 0,13 & 85 & 7893 & 4,9 \\
$\begin{array}{c}\mathrm{CrAlN}- \\
\mathrm{Cr}\end{array}$ & 0,24 & 174 & 20659 & 7,1 \\
\hline
\end{tabular}

Figure 3 presents the images of Rockwell C indents produced for the evaluation of the coating's adhesion. All produced coatings exhibited very high adhesion. The least number of cracks was observed for CrAlN-Al, a bit higher quantity was observed for CrAlN coating while CrAlN-Cr displayed the highest quantity of cracks and also coating delamination. Accordingly, CrAlN-Al coating displayed the best adhesion achieving HF1 level. CrAlN coating exhibited HF2 and CrAlNCr coating the HF3 level of adhesion. 

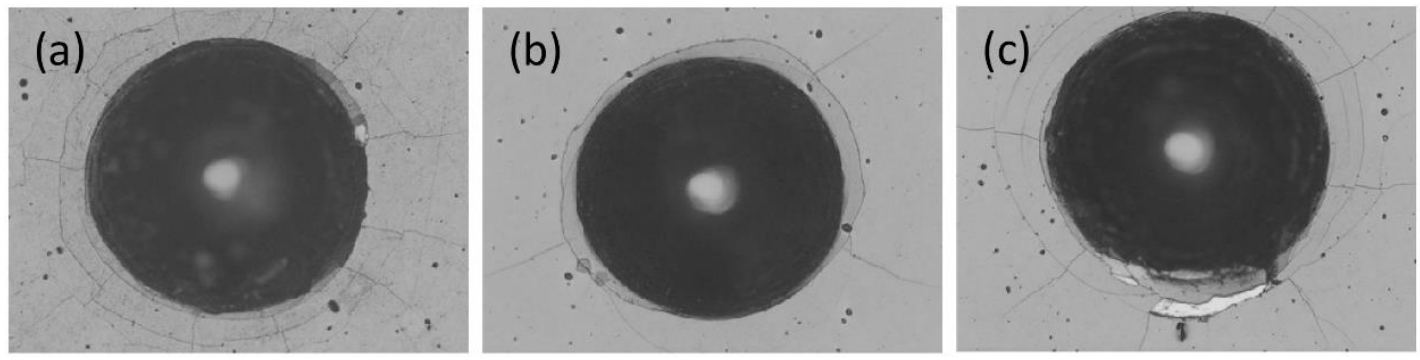

Figure 3. Images of Rockwell C indents, (a) CrAlN; (b) CrAlN-Al and (c) CrAlN-Cr coating.

Values of detachment force obtained for all investigated coatings are for various experiments presented in Figure 4. It can be seen that CrAlN-Al and CrAlN-Cr samples exhibited the highest detachment force, displaying approximately the same values in all experimental conditions. On the other side, the lowest detachment force was obtained for CrAlN samples, for all experimental cases. These values were significantly lower, for $40 \%$ and more than those obtained for CrAlN-Al and CrAlN-Cr sample. The lowest value of detachment force $(46 \mathrm{~kg})$ was determined for the CrAlN sample subjected to CS experiments. Generally, values of detachment force slightly increase with an increase in the period of solidification delay (from CS to DS30).

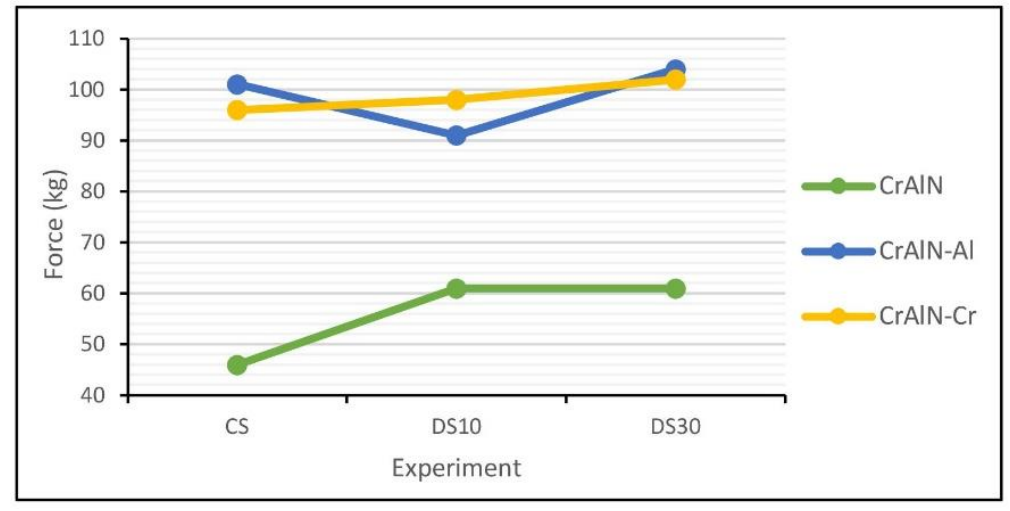

Figure 4. Detachment force of all investigated samples and all experimental conditions.

In order to explain the observed differences in the values of detachment force, and to determine the extent of the sample's soldering wear, samples were analyzed by different microscopy techniques. LOM image of CrAlN-Cr sample after DS30 experiment is presented in Figure 5a. It is a representative example of the coated surface that was in contact with Al-Si-Cu casting. Circular mark $(\phi 22 \mathrm{~mm})$ seen in the middle of a disc sample is the area of the contact established between the casting and the coated surface, Figure 5a. Area outside the circular mark is the untreated sample area. In the contact area, different wear features (regions) were observed. Bright features seen on the sample surface are the aluminum alloy which remained thereafter the detachment test, called soldered aluminum or soldering. Dark features present on the image are areas where the coating delamination occurred. To quantify the areas covered with soldered aluminum and with coating delamination, images were analyzed by image processing software. The representative image of such an analysis is presented in Figure $5 b$. 

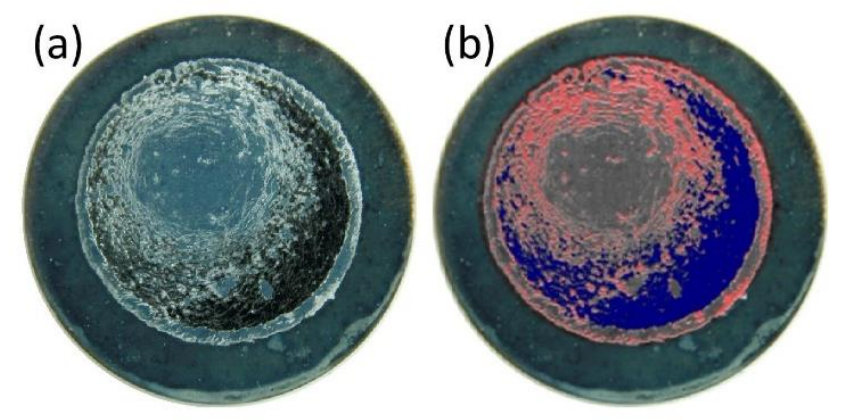

Figure 5. LOM image of CrAlN-Cr sample after DS30 detachment test: (a) appearance of sample surface after the test; (b) image analysis of sample surface, detection of coating delamination (blue color) and soldered aluminum alloy (red color).

To evaluate the coating's wear, after the detachment tests sample surfaces were detailly analyzed by SEM and EDS. These analyses were used for confirming the presence of soldering and delamination on some areas and for distinguishing between these two phenomena.

These results were used to support the analysis of images taken by LOM, i.e. Figure 5b. Images obtained in SEM analysis are presented in Figure 6, while the results of EDS analysis performed on spots indicated in Figure 6c are presented in Table 2. A location on the sample where different wear features can be observed is presented in Figure 6a. In the analyzed region, a lot of coating remained undamaged (solid yellow arrows). Small "islands" that stands out of the surface are soldered aluminum, which covers the whole area of undamaged coating surfaces (solid green arrows). Typical areas with coating delamination are indicated by dashed yellow arrows. In the evaluated area, on few location corrosion products of aluminum alloy attack on the substrate material can be distinguished (dashed rectangle). Image presented in Figure $6 \mathrm{~b}$ is a back-scattering electron image (BSE) of one typical micro area marked with a white rectangle in Figure 6a. The brightest areas in Figure $6 \mathrm{~b}$ indicates delaminated coating, bright gray is the coating material (undamaged or broken) and the darkest features, indicated by a solid green arrow, are soldered aluminum. Dark feature with circular shape (solid black arrow) is a product of a corrosion process of substrate material which occurred through coating growth defect. As can be seen, the corrosion product consists of material similar to the soldered aluminum alloy. Figure $6 \mathrm{c}$ presents a close-up image of a corrosion product and spots of EDS analysis. It can be seen that bulged-feature has an almost ideal circular shape and that its surface is nearly completely covered with a layer of coating. Near this corrosion site, areas with completely detached coatings and regions with broken coating areas can be seen. The surface morphology of a broken coating layer displays step-like features. 


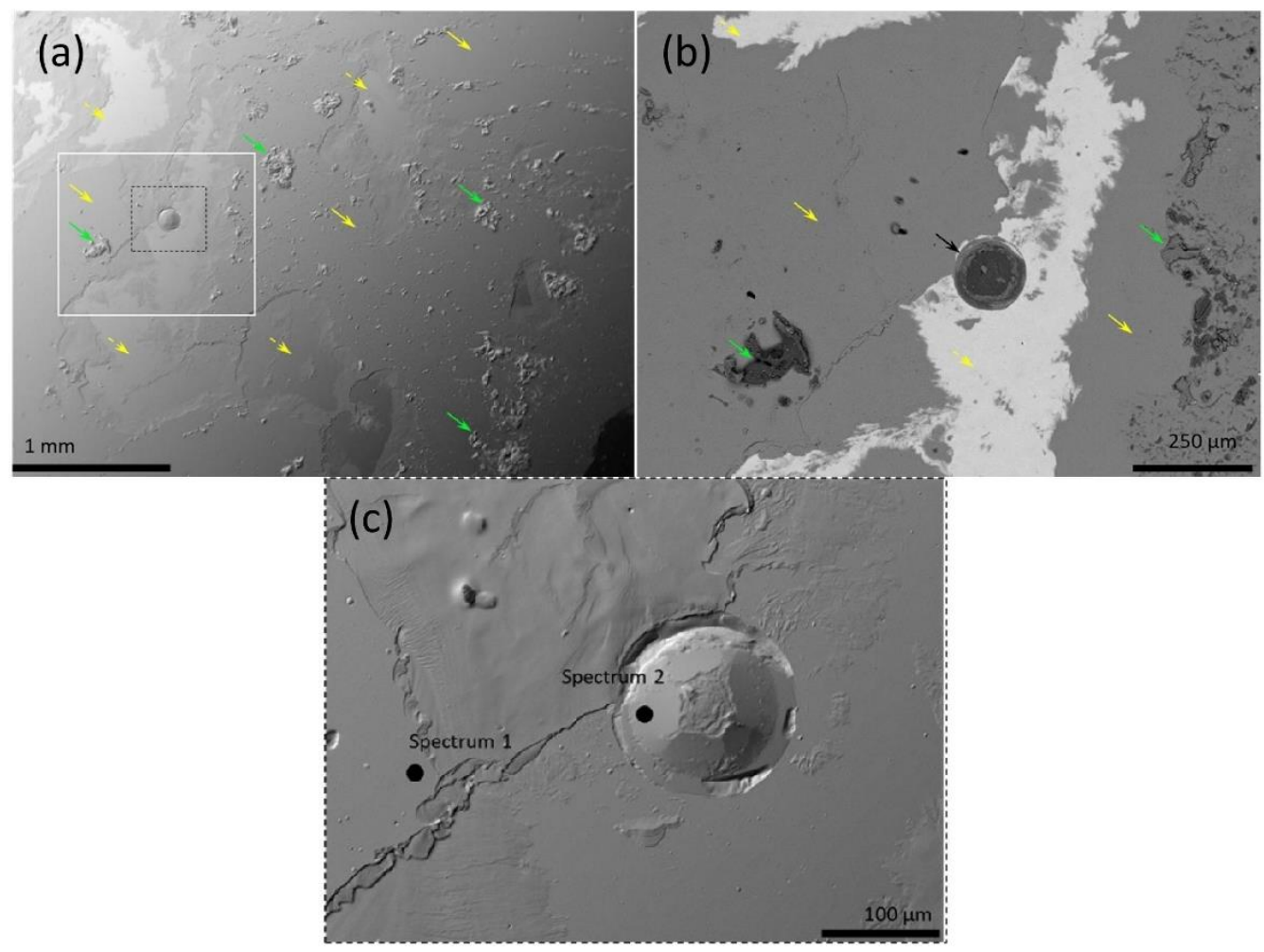

Figure 6. SEM images of the CrAlN-Cr sample surfaces after DS30 detachment test: (a) secondary electron image (SE) of sample area with distinctive wear features, solid yellow arrows indicate undamaged coating surface, dashed yellow arrows indicate coating delamination, solid green arrows indicate soldered aluminum alloy; (b) back-scattering electron (BSE) image of the area marked with a white rectangle in (a) black arrow indicates a substrate corrosion site; (c) SE image of area marked with a black dashed rectangle in (a).

Results of EDS analysis performed on spots in Figure $6 \mathrm{c}$ are presented in Table 2. It is indicated that the bulged feature predominantly consists of $\mathrm{Al}$ and $\mathrm{Si}$, and also of elements contained in steel ( $\mathrm{Fe}, \mathrm{C}, \mathrm{Cr}$ ). The chemical composition of a coating is typical for the CrAlN-Cr sample.

Table 2. EDS analysis performed on the spots indicated in Figure 5a.

\begin{tabular}{cccccccc}
\hline \multicolumn{7}{c}{ Chemical Composition [\%] } \\
\hline Spectrum & $\mathbf{C r}$ & $\mathbf{A l}$ & $\mathbf{N}$ & $\mathbf{C}$ & $\mathbf{S i}$ & $\mathbf{F e}$ & $\mathbf{M g}$ \\
\hline 1 & 75.78 & 7.32 & 14.84 & 1.51 & 0.07 & 0.04 & 0.44 \\
2 & 2.60 & 66.33 & 13.90 & 9.71 & 3.26 & 3.66 & 0.55 \\
\hline
\end{tabular}

The quantitative data obtained by LOM image analysis are for all samples and experiments presented in Figure 7. The whole area of sample-casting contact was $380 \mathrm{~mm}^{2}$. In most of the investigated cases, the areas covered by soldered aluminum were considerably larger than the coating delaminated area. In CS experiments the surfaces of CrAlN and CrAlN-Al samples were only covered with soldered aluminum, while CrAlN-Cr sample suffered also a considerable amount of coating delamination. In DS10 experiments, all samples exhibited very similar behavior, without or with minor coating delamination. The largest difference in samples behavior is observed in DS30 experiment. Generally, in DS30 experiment, the largest areas of coating delamination were observed. CrAlN sample displayed the best behavior in DS30 experiment, CrAlN-Al performed the second while CrAlN-Cr sample displayed the largest areas covered by soldering and delamination. CrAlN sample is the only sample that in all experiments, exhibited just soldered aluminum on its surfaces, with just minor delamination. On the other side, CrAlN-Cr sample exhibited the largest coating delamination in all cases and quite high soldered aluminum areas. 


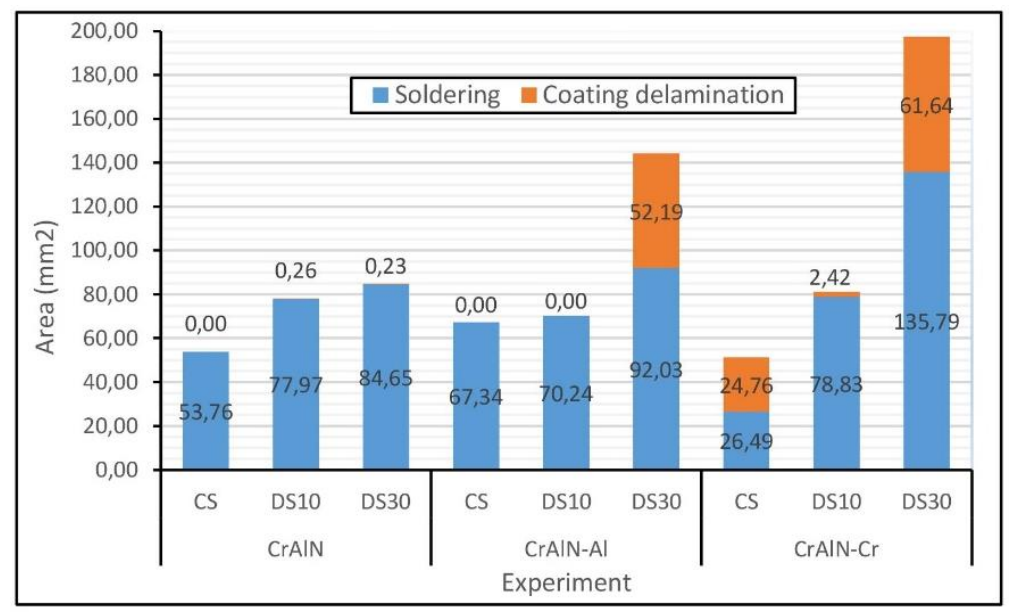

Figure 7. Areal coverage by soldered aluminum and coating delamination on sample surfaces after the detachment tests.

\section{Discussion}

\subsection{Properties of Investigated Coatings}

Surface roughness obtained for all investigated coatings belongs to the group of very fine surface finishes, which is very important for high-quality HPDC tools. The surface roughness (Sq) of investigated coatings directly correlates with the density of growth defects and with coating thickness. Additionally, the samples placed higher in the deposition chamber exhibited larger thickness and more nodular defects, and vice versa. This means, that for the investigated case, the deposition rate varied with height in the chamber. Such variation in deposition rate is attributed to differences in the sputtering rates of metal dominant in that part of the target. $\mathrm{Cr}$ has a higher sputtering rate than $\mathrm{Al}$ and consequently, the coatings containing more $\mathrm{Cr}$ are thicker than those with more Al. Higher roughness of thicker coatings is addressed to the fact that they are produced at higher deposition rates [22,23]. Additionally, the higher deposition rate may increase the probability of nodular defects formation, which is usually the case for deposition system used in this investigation.

Very high adhesion of all investigated coatings and quite ductile behavior under load is attributed to the presence of ductile nanolayers in the coating structure, the AlN layers. Presence of these ductile layers means that these coatings can better accommodate the plastic deformation of the substrate without cracking or delamination [24]. The coatings with higher Al content basically possess higher $\mathrm{Al}$ content in CrAlN nanolayers of their CrAlN/CrN/CrAlN/AlN structure. As such, this coating should be softer and more ductile than the one with high $\mathrm{Cr}$ content [25]. The obtained levels of coatings adhesion and the observed coating ductility make these coatings appropriate for application on HPDC tools. The observed behavior of the coating under mechanical load is promising in the reduction of thermal cycling fatigue which is usually a limiting factor for application of PVD coatings on HPDC tools.

\subsection{Coatings Soldering Wear}

The cast alloy soldering process-induced wear of all investigated samples which manifested in two forms. The first form is the cast alloy soldering. This kind of wear manifested in the formation of layers and islands of cast alloy material on coated surfaces (Figure 6a green arrows). Such wear occurs due to mechanical interlocking of surfaces and/or to chemical bonding between the cast alloy and coating material $[26][5,20,26]$. However, information about this kind of wear is still scarce in the literature. The second form of wear is the coating delamination, which refers to the detachment of the coating layer from the substrate (Figure 6a yellow dashed arrows). This kind of wear is initiated by corrosion of substrate material by aluminum alloy through the coating growth defects (Figure 6c). 
In this process, intermetallic phases (Al-Fe-Si) formed in the cast alloy and the substrate material (Table 2), which resulted in strong bonding between the casting and the sample. Intermetallic phases that formed in the substrate material, acted as hooks, which during detachment experiment rippedoff the coating from the substrate [26]. This kind of wear process is completely dependent on the type, morphology, density of coating growth defects and it is also dependent on the period of exposure to molten alloy [27].

Considering that cast alloy soldering is a predominant form of wear observed on most of the evaluated samples (Figure 7), it is suggested that the employed experimental conditions predominantly simulate this form of wear. Quantification of both forms of wear indicated different wear performance of investigated coatings. The amount (area) of the soldering wear indicates the soldering tendency of paired material, while coating delamination indicates the coatings corrosion resistance to molten aluminum alloy.

CrAlN and CrAlN-Al samples exhibited the least soldering in all experimental conditions, while CrAlN-Al samples displayed also some delamination in DS30 experiment. Considering that CrAlN sample in all investigated cases exhibited mostly the least soldering and just minor delamination, it is suggested that this coating has the highest both soldering and corrosion resistance. This result is quite contrary to the results obtained by Wang et al for $\mathrm{Cr}_{0.54} \mathrm{Al}_{0.46} \mathrm{~N}$ and $\mathrm{Al} \mathrm{l}_{0.67} \mathrm{Cr} 0.33 \mathrm{~N}$ coatings in [20]. However, their coatings were produced by cathodic arc and some doubts are raised regarding the quality, control, and repetitiveness of the casting method (aluminum adhesion test) that they had applied. Additionally, the complex nanolayer design of investigated coating should induce quite different behavior of these coatings. CrAlN-Cr sample displayed the largest areas covered with soldering and the largest extent of coating delamination. Largest delamination observed for CrAlNCr sample is in agreement with the highest density of nodular defects determined for this coating (Table 1) and with the lowest coating adhesion, Figure 3. However, a direct correlation of defects density with the number of nodular defects is not observed for CrAlN-Cr and CrAlN-Al samples. This indicates that an explanation of their behavior would require a more detailed investigation of the causes of delamination phenomena. CrAlN-Cr sample is ranked as a coating with the lowest soldering and corrosion resistance among the investigated coatings. This finding is in agreement with propositions of Lin et al [12], who proposed that most appropriate CrAlN coatings for HPDC tools should have $\mathrm{Al}: \mathrm{Cr} \geq 1 \mathrm{~s}$.

Cast alloy soldering is usually not detrimental to coating integrity but affects the performance of HPDC tool, the casting quality, and the production economy. The tool with pronounced soldering can be cleaned and continued to be used. On the other side, coating delamination is complete coating wear and as such a sign that the tool element has to be exchanged and/or recoated.

\subsection{Detachment Force}

Both soldering and substrate corrosion through coating growth defects, affect the bonding achieved between the cast alloy and the coated element. This indicates that the value of detachment force has two components and that its value depends on a specific contribution (share) of each component. Based on the observed relations between worn areas and corresponding values of detachment force (Figures 4 and 7) it is postulated that the cast alloy soldering component has a larger effect on the value of detachment force than the corrosion component. This is also in agreement with the findings of several authors from the field, which found that the strength of the intermetallic phases (Al-Fe-Si) were considerably lower than that of the casting alloy and/or steel substrate material [20,28]. Additionally, frequent formation of cracks in these layers adds up to this effect [20]. Our postulate is confirmed by the values of detachment force measured for CrAlN coating, which correlates very well with the corresponding area of soldered aluminum (Figures 4 and 7).

The two samples, CrAIN and CrAlN-Al, in CS and DS10 experiments displayed none or just minor coating delamination. They exhibited quite comparable soldered area but their values of detachment force significantly differ. Such behavior suggests that, besides soldering and corrosion, an additional (hidden) component influences the detachment force. It is believed that this component should be the "pure" sticking of cast alloy to coated surfaces. By the pure-sticking, a process of 
adhesive bonding of cast alloy to coated surfaces is considered. Under the applied load the achieved bond breaks, on the interface formed between them, and leave no remnants of cast alloy on coated surfaces. Evidently, this kind of casting-coating bonding depends on the affinity of cast alloy toward coating surfaces. Therefore, coatings with lower pure-sticking component are desired for application on HPDC tools and should be the focus of development.

The lowest values of detachment force obtained for CrAlN sample corresponds to the smallest area with soldering and delamination and to the least extent of pure-sticking phenomena. Compared to CrAlN sample, higher values of detachment force of CrAlN-Al sample can be only attributed to higher affinity of Al-Si-Cu cast alloy toward Al-rich CrAlN coating, i.e. to its higher pure-sticking tendency. The high values of detachment force observed for CrAlN-Cr sample are a consequence of the combined effect of high soldering, corrosion tendency, and pure-sticking tendency. A slightly increasing trend of detachment force with increased time of delay is attributed to the process kinetics which enhance all bonding effects between the casting and the coating material.

For future development and evaluation of soldering resistant coatings, the most important is to isolate only the soldering and sticking phenomena. Therefore, for the studies using the detachment test, it is proposed to avoid the coating delamination effects by adjusting the casting process, i.e. to shorten the solidification delay.

\section{Conclusions}

In this study, the soldering performance of nanolayer CrAlN (CrAlN/CrN/CrAlN/AlN) coating with three chemical compositions was evaluated in contact with Al-Si-Cu alloy. The soldering performance was evaluated by the detachment test performed with three periods of casting solidification. From the conducted investigation the following conclusions are drawn:

- All investigated coatings exhibited very fine surface finish, while the density of growth defects was found to be dependent on coatings chemical composition. All coatings were characterized by very good adhesion and high cracking resistance.

- After the detachment tests, two kinds of wear were detected on the surfaces of all investigated coatings. The one is the soldering which induced the formation of cast alloy layers on the surfaces of all investigated coatings. The other is the substrate corrosion through growth defects, which during the casting detachment induced coating delamination.

- CrAlN coating with balanced Al:Cr composition exhibited the highest soldering and corrosion resistance. CrAlN coating with higher Al content displayed quite good performance with slightly lower corrosion resistance (larger coating delamination) in longer tests. CrAlN coating with highest $\mathrm{Cr}$ content exhibited the lowest soldering and corrosion resistance.

- CrAlN coating with balanced Al:Cr composition exhibited the lowest detachment force while CrAlN coatings with higher $\mathrm{Al}$ and $\mathrm{Cr}$ content displayed quite similar and considerably higher values of detachment force.

- It was determined that the values of detachment force depend on three phenomena (components), which govern the casting-coating bonding. These are: the cast alloy soldering, substrate corrosion through growth defects, and the "pure" sticking of cast alloy to coated surfaces. It was found that the pure-sticking component induced the main differences between the coatings with different chemical composition.

Author Contributions: Conceptualization, D.K., L.K. and P.T.; methodology, D.K, L.K., and P.T.; validation, V.T., and A.M.; investigation, D.K., L.K., P.T., and V.T.; resources, B.Š., P.P. and M.Č.; writing-original draft preparation, P.T., and D.K.; writing-review and editing A.M., L.K., and B.Š.; visualization, A.M. and V.T.; supervision, B.Š., P.P. and M.Č.; project administration A.M., P.P. and B.Š.; funding acquisition, A.M., B.Š., P.P and M.Č.

Funding: This work was financially supported by the Serbian Ministry of Education, Science and Technological Development grant III-45006 and by the Provincial Secretariat for Higher Education and Scientific Research of 
Vojvodina, Serbia grant 114-451-2192/2016-02. This work was also funded by the Serbian-Slovenian bilateral project (2018-2019) grant 48.

Acknowledgments: We acknowledge GasTeh d.o.o. (Indjija, Serbia) for the fabrication of the samples and Termometal d.o.o. (Ada, Serbia) for heat treatment. Special thanks to the colleges from the BioSense Institute (Novi Sad, Serbia) for conducting the Scanning electron microscopy (SEM) analysis.

Conflicts of Interest: The authors declare no conflict of interest.

\section{References}

1. Chen, Z.W.; Jahedi, M.Z. Die erosion and its effect on soldering formation in high pressure die casting of aluminium alloys. Mater. Des. 1999, 20, 303-309, doi:10.1016/S0261-3069(99)00035-7.

2. Persson, A.; Hogmark, S.; Bergström, J. Failure modes in field-tested brass die casting dies. J. Mater. Process. Technol. 2004, 148, 108-118, doi:10.1016/j.jmatprotec.2004.01.052.

3. Gobber, F.; Pisa, A.; Ugues, D.; Lombardo, S.; Fracchia, E.; Rosso, M. Study of the Effect of SurfaceRoughness of Dies and Tooling for HPDC on Soldering. In Light Metals 2018; pp. 977-981 ISBN 9783319722832.

4. Chen, Z.W. Formation and progression of die soldering during high pressure die casting. Mater. Sci. Eng. A 2005, 397, 356-369, doi:10.1016/j.msea.2005.02.057.

5. Terek, P.; Kovačević, L.; Miletić, A.; Panjan, P.; Baloš, S.; Škorić, B.; Kakaš, D. Effects of die core treatments and surface finishes on the sticking and galling tendency of Al-Si alloy casting during ejection. Wear 2016, 356-357, 122-134, doi:10.1016/j.wear.2016.03.016.

6. Han, Q.Y. Mechanism of die soldering during aluminum die casting. China Foundry 2015, 12, $136-143$.

7. Zhu, H.; Guo, J.; Jia, J. Experimental study and theoretical analysis on die soldering in aluminum die casting. J. Mater. Process. Technol. 2002, 123, 229-235, doi:10.1016/S0924-0136(01)01174-8.

8. Lorusso, M.; Ugues, D.; Oliva, C.; Ghisleni, R. Failure modes of PVD coatings in molten Al-alloy contact. Acta Metall. Slovaca 2013, 19, 30-42, doi:10.12776/ams.v19i1.84.

9. Joshi, V.; Srivastava, A.; Shivpuri, R.; Rolinski, E. Investigating ion nitriding for the reduction of dissolution and soldering in die-casting shot sleeves. Surf. Coatings Technol. 2003, 163-164, 668-673, doi:10.1016/S02578972(02)00693-X.

10. Peter, I.; Rosso, M.; Gobber, F.S. Study of protective coatings for aluminum die casting molds. Appl. Surf. Sci. 2015, 358, 563-571, doi:10.1016/j.apsusc.2015.08.013.

11. Terek, P.; Kovačević, L.; Miletić, A.; Kukuruzović, D.; Škorić, B.; Drnovšek, A.; Panjan, P. Ejection performance of coated core pins intended for application on high pressure die casting tools for aluminium alloys processing. Tribol. Ind. 2017, 39, 334-339, doi:10.24874/ti.2017.39.03.08.

12. Lin, J.; Carrera, S.; Kunrath, A.O.; Zhong, D.; Myers, S.; Mishra, B.; Ried, P.; Moore, J.J. Design methodology for optimized die coatings: The case for aluminum pressure die-casting. Invited paper B7-1-1, ICMCTF, presented Monday May 2nd, 2005, San Diego. Surf. Coatings Technol. 2006, 201, 2930-2941, doi:10.1016/j.surfcoat.2006.06.024.

13. Paiva, J.; Fox-Rabinovich, G.; Locks Junior, E.; Stolf, P.; Seid Ahmed, Y.; Matos Martins, M.; Bork, C.; Veldhuis, S. Tribological and Wear Performance of Nanocomposite PVD Hard Coatings Deposited on Aluminum Die Casting Tool. Materials (Basel). 2018, 11, 358, doi:10.3390/ma11030358.

14. Bobzin, K.; Brögelmann, T.; Hartmann, U.; Kruppe, N.C.; Cáceres, C..; Djurdjevic, M..; Stockwell, T..; Sokolowski, J..; Bobzin, K.; Brögelmann, T.; et al. Analysis of CrN/AlN/Al2O3 and two industrially used coatings deposited on die casting cores after application in an aluminum die casting machine. Surf. Coatings Technol. 2016, 308, 374-382, doi:10.1016/j.surfcoat.2016.09.040.

15. Tentardini, E.K.; Aharanov, R., Chellapilla, S., Shivpuri, R., Lakare, A.; Castro, M.; Kunrath, A.O.; Moore, J.J.; Kwietniewski, C.; Baumvol, I.J.R. Reactivity between aluminum and (Ti,Al)N coatings for casting dies. Thin Solid Films 2008, 516, 3062-3069, doi:10.1016/j.tsf.2007.10.088.

16. Salman, A.; Gabbitas, B.L.; Cao, P.; Zhang, D.L. The performance of thermally sprayed titanium based composite coatings in molten aluminium. Surf. Coatings Technol. 2011, 205, 5000-5008, doi:10.1016/j.surfcoat.2011.04.096.

17. Terek, P.; Kovačević, L.; Miletić, A.; Kukuruzović, D.; Baloš, S.; Škorić, B. Improved ejection test for evaluation of soldering tendency of cast alloy to die core materials. J. Mater. Process. Technol. 2019, 266, 114124, doi:10.1016/j.jmatprotec.2018.10.038. 
18. Gopal, S.; Lakare, A.; Shivpuri, R. Evaluation of thin film coatings for erosive-corrosive wear prevention in die casting dies. Surf. Eng. 1999, 15, 297-300, doi:10.1179/026708499101516632.

19. Shivpuri, R.; Yu, M.; Venkatesan, K.; Chu, Y.L. A study of erosion in die casting dies by a multiple pin accelerated erosion test. J. Mater. Eng. Perform. 1995, 4, 145-153, doi:10.1007/BF02664107.

20. Wang, B.; Bourne, G.R.; Korenyi-Both, A.L.; Monroe, A.K.; Midson, S.P.; Kaufman, M.J. Method to evaluate the adhesion behavior of aluminum-based alloys on various materials and coatings for lube-free die casting. J. Mater. Process. Technol. 2016, 237, 386-393, doi:10.1016/j.jmatprotec.2016.06.031.

21. Kukuruzović, D.; Terek, P.; Kovačević, L.; Škorić, B.; Miletić, A.; Panjan, P.; Čekada, M. Evaluation of Soldering Resistance of Craln Coatings Intended for Application on High Pressure Die Casting Tools. Proc. Eng. Sci. 2019, 1, 278-284, doi:10.24874/PES01.01.035.

22. Petrov, I.; Barna, P.B.; Hultman, L.; Greene, J.E. Microstructural evolution during film growth. J. Vac. Sci. Technol. A Vacuum, Surfaces, Film. 2003, 21, S117-S128, doi:10.1116/1.1601610.

23. Panjan, P.; Gselman, P.; Kek-Merl, D.; Čekada, M.; Panjan, M.; Dražić, G.; Bončina, T.; Zupanič, F. Growth defect density in PVD hard coatings prepared by different deposition techniques. Surf. Coatings Technol. 2013, 237, 349-356, doi:10.1016/j.surfcoat.2013.09.020.

24. Torres, E.; Ugues, D.; Brytan, Z.; Perucca, M. Development of multilayer coatings for forming dies and tools of aluminium alloy from liquid state. J. Phys. D. Appl. Phys. 2009, 42, 105306, doi:10.1088/00223727/42/10/105306.

25. Lin, J.; Mishra, B.; Moore, J.J.; Sproul, W.D. Microstructure, mechanical and tribological properties of Cr1-xAlxN films deposited by pulsed-closed field unbalanced magnetron sputtering (P-CFUBMS). Surf. Coatings Technol. 2006, 201, 4329-4334, doi:10.1016/j.surfcoat.2006.08.090.

26. Terek, P.; Kovačević, L.; Miletić, A.; Škorić, B.; Kovač, J.; Drnovšek, A. Metallurgical Soldering of Duplex CrN Coating in Contact with Aluminum Alloy. Coatings 2020, 10, 303, doi:10.3390/coatings10030303.

27. Persson, A.; Bergström, J. Influence of deposition temperature and time during PVD coating of CrN on corrosive wear in liquid aluminium. Surf. Coatings Technol. 2001, 147, 42-47, doi:http://dx.doi.org/10.1016/S0257-8972(01)01366-4.

28. Terek, P. Application of surface engineering technologies for improvement of die casting tools quality, University of Novi Sad, 2016.

(C) 2020 by the authors. Submitted for possible open access publication under the terms and conditions of the Creative Commons Attribution (CC BY) license (http://creativecommons.org/licenses/by/4.0/). 